\title{
Phytochemical evaluation and in vitro antioxidant studies of selected species of Gomphostemma Wall. ex Benth. from Western Ghats
}

\author{
Sajitha M. K., Thoppil J. E. \\ Cell and Molecular Biology Division, Department of Botany, University of Calicut, Malappuram, Kerala, India.
}

\begin{abstract}
Plants are a rich source of bioactive compounds and have played a vital role in traditional medicine. Plant derived compounds are proved to have less side effects as compared to synthetic compounds. However, a truncated history on the contribution of plants to medicine together with lack of validation of plant derived components have led to massive research in phytochemistry and allied fields. Present study was intended to identify as well as to assess and compare different phytochemicals and antioxidant potential of selected taxa of Gomphostemma endemic to Western Ghats. Methanolic extracts of aerial parts of Gomphostemma heyneanum var. heyneanum, Gomphostemma heyneanum var. rottleri and Gomphostemma eriocarpum were subjected to preliminary phytochemical screening. Quantitative estimation of phenols and flavonoids was done with Folin-Ciocalteu method and modified Aluminium chloride method respectively. Antioxidant potential was examined by DPPH assay, Hydroxyl radical scavenging assay and Reducing power activity. Preliminary screening indicated the presence of many secondary metabolites like phenols, flavonoids, alkaloids, terpenoids and steroids. Results of quantitative estimation revealed that $G$. heyneanum var. heyneanum has the highest concentration of phenols and flavonoids. Antioxidant potential determined in terms of inhibition percentage also displayed that Gomphostemma species have significant radical scavenging activity. The antioxidant potential exhibited by the plant species may be attributed to their phenol and flavonoid content.
\end{abstract}

Keywords: Phytochemical constituents, Gomphostemma, Quantitative estimation, Total phenolics, Flavonoids, Antioxidant activity, DPPH assay, Hydroxyl radical scavenging assay, Reducing power activity.

Article Info: Received 13 Oct 2018; Review Completed 24 Nov 2018; Accepted 26 Nov 2018; Available online 15 Dec 2018

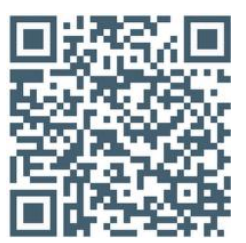

Cite this article as:

Sajitha MK, Thoppil J.E., Phytochemical evaluation and in vitro antioxidant studies of selected species of

Gomphostemma Wall. ex Benth. from Western Ghats, Journal of Drug Delivery and Therapeutics. 2018; 8(6-s):32-37

DOI: http://dx.doi.org/10.22270/jddt.v8i6-s.2074

*Address for Correspondence:

Sajitha M. K., Thoppil J. E., Cell and Molecular Biology Division, Department of Botany, University of Calicut, Malappuram, Kerala, India.

\section{INTRODUCTION}

Plants are nature's pharmaceutical treasure chest as they form one of the major bio resources of compounds having miraculous effect in preventing and treating many diseases along with improving the general health of living organisms. Herbal plants thus form the backbone of traditional system of treatments throughout the globe and contribute compounds to pharmaceutical industry for drug development. Secondary metabolites like phenols, terpenes, flavonoids, alkaloids, phytosterols etc. which are produced naturally by the plants are held responsible for the therapeutic potential exhibited by them.

Free radicals are molecules and atoms with unpaired electrons in their outer shell. They are highly reactive and are formed in processes that involve oxygen. Free radicals that originate from oxygen are called reactive oxygen species (ROS), whereas free radicals that originate from the reaction of oxygen with nitrogen are considered as a subclass of free radicals and are called reactive nitrogen species (RNS) ${ }^{1}$. Free radicals often called as ROS (Reactive Oxygen Species) are produced in the body of all organisms as a result of innumerable enzymatic reactions and is balanced by body's endogenous antioxidant system. But increase in ROS or decrease in the cellular antioxidant capacity can cause cellular oxidative stress. In either case it results in direct or indirect ROS-mediated damage of nucleic acids, proteins and lipids 2. There is increasing evidence of ROS involvement in implicating carcinogenesis, ageing, neurodegeneration, renal and hepatic disorders ${ }^{3}$. Plant derived antioxidants are proved to be with less side effects and good radical scavenging activity. It is because of this that antioxidants of plant origin can be a safe replacement for harmful and synthetic antioxidants 4 .

Lamiaceae, a prominent medicinal aromatic family is very popular in folk medicine to treat various health problems such as throat infections, stomach disorders, ulcer, spasm, cold, haemorrhages and skin problems. Species of this botanical family contain a wide range of bioactive constituents that make them very important from 
pharmacological point of view. Gomphostemma Wall. ex Benth. is an under exploited taxa of Lamiaceae. It is reported to have ethnomedicinal uses in treating diarrhoea, dysentery, arthritis and in curing inflammation by insect stings 5, 6. Recently, there are reports on the antimalarial property of terpenes isolated from Gomphostemma ${ }^{7}$. Members of Gomphostemma reported from South India are endemic to Western Ghats and to this date not many reports are available regarding their phytochemical constituents and bioactivity. Present study is intended to screen the selected taxa of Gomphostemma endemic to Western Ghats viz., Gomphostemma heyneanum Wall. ex Benth. var. heyneanum, Gomphostemma heyneanum var. rottleri Prain and Gomphostemma eriocarpum Benth. for their phytochemicals and antioxidative potential.

\section{MATERIALS AND METHODS}

Aerial parts of selected Gomphostemma spp. were collected from their natural populations in Nelliyampathy forest area of Palakkad district and Ranni forest area of Pathanamthitta district, Kerala. Plants were identified and voucher specimens (CALI 123772 for G. heyneanum var. heyneanum, CALI 123773 for G. heyneanum var. rottleri, CALI 123774 for G. eriocarpum) were deposited in Calicut University Herbarium.

\section{Preparation of plant extract}

Twenty grams of dry powder of each plant material was subjected to soxhlet extraction using methanol as solvent. All methanolic extracts were concentrated in a rotary evaporator at $40^{\circ} \mathrm{C}$. The crude extracts thus obtained were stored in refrigerator at $4^{\circ} \mathrm{C}$ and used for further analysis.

\section{Preliminary phytochemical screening}

Methanolic extracts of selected taxa were subjected to qualitative phytochemical analysis to identify the presence of various secondary phytoconstituents as per standard procedures 8,9 .

Test for phenols: A fraction of the extract was treated with $5 \%$ ferric chloride solution. Appearance of deep blue or black colour indicates the presence of phenols.

\section{Tests for flavonoids:}

Alkaline reagent test: To $2 \mathrm{~mL}$ of the extract, a few drops of $20 \%$ sodium hydroxide were added. Appearance of yellow coloration which disappears on adding dilute hydrochloric acid infers the presence of flavonoids.

\section{Test for alkaloids:}

Wagner's Test: To sample solution Wagner's reagent was added and formation of reddish precipitate is taken as evidence for the presence of alkaloids.

\section{Tests for terpenoids:}

Salkowski test: To a fraction of extract, $2 \mathrm{~mL}$ of chloroform was added followed by the addition of conc. $\mathrm{H}_{2} \mathrm{SO}_{4}$ along the sides of the test tube to form a layer. Formation of reddish brown coloration at the interface of the solution infers the presence of terpenoids.

\section{Test for steroids:}

Liebermann -Burchard test: To $2 \mathrm{~mL}$ of methanolic extract, few drops of chloroform, acetic anhydride and conc. $\mathrm{H}_{2} \mathrm{SO}_{4}$ were added and formation of dark pink or red colour is an indication of the presence of steroids.

\section{Test for tannins:}

Braymer's test: About $2 \mathrm{~mL}$ of extract was treated with $10 \%$ ferric chloride solution and appearance of blue or greenish coloration indicates the presence of tannins.

Test for saponins: In a test tube $1 \mathrm{~mL}$ of extract was taken and $20 \mathrm{~mL}$ of water was added. It was then shaken vigorously and observed for the formation of foam layer stable for $15 \mathrm{~min}$ which is taken as an indication for the presence of saponins.

\section{Estimation of total phenolic content}

The total phenolic content of the plant extracts was determined using a modified Folin- Ciocalteu method 10. Gallic acid was used as the standard. An aliquot of sample/standard was mixed with $0.5 \mathrm{~mL}$ of distilled water followed by the addition of $1.25 \mathrm{~mL}$ of Folin - Ciocalteu reagent. The mixture was allowed to stand for $6 \mathrm{~min}$ before adding $1.25 \mathrm{~mL}$ of $7 \% \mathrm{Na}_{2} \mathrm{CO}_{3}$ and the final volume was made to $3 \mathrm{~mL}$ with distilled water. The whole reaction mixture was incubated in dark at room temperature for 90 min. The absorbance was read at $760 \mathrm{~nm}$ against blank (distilled water) in a spectrophotometer (Elico SL 218, India). All values were expressed as mean in $\mathrm{mg}$ of gallic acid equivalents per gram of dry weight (mg GAE/g DW) \pm standard error of mean (SEM) for three replications.

\section{Estimation of total flavonoid content}

The total flavonoid content was determined with the aluminium chloride colorimetric method with slight modification 11. Quercetin was used as the standard. An aliquot of standard/sample added to $75 \mu \mathrm{l}$ of $7 \% \mathrm{NaNO}_{2}$ solution and mixed for $6 \mathrm{~min}$. before adding $0.15 \mathrm{~mL}$ of $\mathrm{AlCl}_{3}(10 \%)$. This was allowed to stand for $5 \mathrm{~min}$. followed by the addition of $1 \mathrm{M} \mathrm{NaOH}$ and the final volume was made to $2.5 \mathrm{~mL}$. The absorbance of the final mixture was determined at $510 \mathrm{~nm}$. The total flavonoid content was expressed as mg quercetin equivalent per gram dry weight (mg QE/g DW) \pm standard error of mean (SEM) for three replications.

\section{Assessment of antioxidant activity}

\section{DPPH radical scavenging assay}

The scavenging activity of DPPH (1, 1-diphenyl-2picrylhydrazyl) free radical by plant extracts was measured using accepted method with slight modification 12. Ascorbic acid was used as reference standard for comparison. Extracts/ reference standard $(20 \mu \mathrm{l})$ of different concentrations $(12.5-200 \mu \mathrm{g} / \mathrm{ml})$ was mixed with $1.48 \mathrm{~mL}$ of DPPH $(0.1 \mathrm{mM})$ solution. A control without test compound but with equivalent amount $(20 \mu \mathrm{L})$ of distilled water and DPPH solution was also prepared. The reaction mixture was incubated in room temperature for $20 \mathrm{~min}$ and absorbance was read at $517 \mathrm{~nm}$ with methanol as blank. The inhibition percent was calculated from the following equation:

$$
\% \text { inhibition }=\frac{A_{\text {control }}-A_{\text {test sample }}}{A_{\text {control }}} \times 100
$$

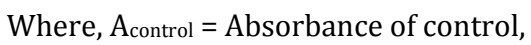
$A_{\text {test sample }}=$ Absorbance of sample/standard.

\section{Hydroxyl radical scavenging assay}

Hydroxyl radical scavenging was assayed with slight modification ${ }^{13}$. Gallic acid was used as reference standard. Different concentration of samples/ reference standard $(125-2000 \mu \mathrm{g} / \mathrm{mL})$ were mixed with $500 \mu \mathrm{L}$ reaction mixture (2 deoxy 2 ribose $(2.8 \mathrm{mM}), \mathrm{FeCl}_{3}(100 \mu \mathrm{M})$, EDTA 
$(100 \mu \mathrm{M}), \mathrm{H}_{2} \mathrm{O}_{2}(1.0 \mathrm{mM})$, ascorbic acid $(100 \mu \mathrm{M})$ in $\mathrm{KH}_{2} \mathrm{PO}_{4}$ - KOH buffer (20 mM pH 7.4) and made up to a final volume of $1 \mathrm{~mL}$. A control without the test compound, but with equivalent amount of distilled water was taken. After incubation for 1 hour at $37^{\circ} \mathrm{C}, 1 \mathrm{ml}$ of $2.8 \%$ TCA and then $1 \mathrm{~mL} 1 \%$ aqueous TBA was added and the mixture was incubated at $90^{\circ} \mathrm{C}$ for 15 minutes to develop the colour. After cooling, absorbance was measured at $532 \mathrm{~nm}$ against a blank solution. The inhibition percentage was calculated from the following equation:

$$
\% \text { inhibition }=\frac{A_{\text {control }}-A_{\text {test sample }}}{A_{\text {control }}} \times 100
$$

Where, $A_{\text {control }}=$ Absorbance of control, Atest sample = Absorbance of sample $/$ standard.

\section{Reducing power assay}

The reducing power of extracts was determined by the method of Yen and Duh ${ }^{14}$. Quercetin was the reference standard. Different concentration of extracts/reference standard $(125-2000 \mu \mathrm{g} / \mathrm{mL})$ was mixed with $2.5 \mathrm{ml}$ of phosphate buffer $(200 \mathrm{mM})(\mathrm{pH} 6.6)$ and $2.5 \mathrm{ml}$ of $1 \%$ potassium ferric cyanide was added. The reaction mixture was boiled for 20 minutes at $50^{\circ} \mathrm{C}$. A control without the test compound was also taken. After incubation, $2.5 \mathrm{ml}$ of $10 \%$ TCA was added to the mixtures followed by centrifugation for 10 minutes. The upper layer was mixed with $5 \mathrm{~mL}$ of distilled water and $1 \mathrm{~mL}$ of $0.1 \%$ ferric chloride was added. The absorbance was read at $700 \mathrm{~nm}$.

\section{Statistical analysis}

All data are given as the mean \pm standard error of mean (SEM) for three replication. IC $_{50}$ values were calculated with GraphPad prism Version 7 for Windows (GraphPad Software Inc).

\section{RESULTS}

The preliminary phytochemical screening of aerial parts of selected taxa of Gomphostemma revealed the presence of phytoconstituents like phenols, flavonoids, alkaloids, terpenoids and steroids. Whereas tannins and saponins were found to be absent. The results of qualitative phytochemical screening are shown in Table 1.

Table 1: Results of qualitative phytochemical analysis of selected taxa of Gomphostemma from Western Ghats.

\begin{tabular}{|c|c|c|c|c|}
\hline Phytochemical components & Tests & GHH & GHR & GE \\
\hline Phenols & Ferric chloride test & + & + & + \\
\hline Flavonoids & Alkaline reagent test & + & + & + \\
\hline Alkaloids & Wagner's test & + & + & + \\
\hline Terpenoids & Salkowski test & + & + & + \\
\hline Steroids & Liebermann -Burchard test & + & + & + \\
\hline Tannins & Braymer's test & - & - & - \\
\hline Saponins & Foam test & - & - & - \\
\hline
\end{tabular}

(+) / (-) indicates presence/absence. GHH- G. heyneanum var. heyneanum, GHR- G. heyneanum var. rottleri, GE - G. eriocarpum.

\section{Total phenolic content}

Phenolic compounds from natural source are well identified as potent antioxidants. Total phenols in plant extracts were estimated with Folin - Ciocalteu reagent in terms of Gallic acid standard. The result obtained shows that $G$. heyneanum var. heyneanum has a higher amount of phenolic content (260.31 mg GAE/g DW) as compared to other two taxa (Table 2).

\section{Total flavonoid content}

Flavonoids are phytoconstituents with a wide range of biological and pharmacological activities especially antioxidant property. Total favonoids was determined by spectrometric method with aluminium chloride method as described above. The content of flavonoids was expressed in terms of quercetin equivalents. The summary of quantities of flavonoid estimated in the tested plant extracts is shown in Table 2. Highest concentration of flavonoid was measured in G. heyneanum var. heyneanum (129.22 $\mathrm{mg}$ QE/g DW) followed by G. heyneanum var. rottleri, whereas lowest flavonoid content was measured in G. eriocarpum.

Table 2: Total phenolic content and total flavonoid content of selected species of Gomphostemma from Western Ghats.

\begin{tabular}{|l|l|l|}
\hline Plant & $\begin{array}{l}\text { Total phenolic content } \\
\text { (mg GAE/g DW) }\end{array}$ & $\begin{array}{l}\text { Total flavonoid content } \\
\text { (mg QE/g DW) }\end{array}$ \\
\hline GHH & $260.31 \pm 11.62$ & $129.22 \pm 10.658$ \\
\hline GHR & $178.78 \pm 9.32$ & $88.96 \pm 0.550$ \\
\hline GE & $32.56 \pm 3.18$ & $33.69 \pm 0.528$ \\
\hline
\end{tabular}

Total phenolic content analysed as GAE mg/g of dry weight of sample; Total flavonoid content analysed as QE mg/g of dry weight of sample; GAE is gallic acid equivalents, QE is quercetin equivalents; GHH- G. heyneanum var. heyneanum, GHR- G. heyneanum var. rottleri, GE - G. eriocarpum. Data expressed as Mean \pm SE of three replicates.

\section{DPPH assay}

DPPH assay is an easy, rapid and sensitive method to survey the free radical scavenging ability of a compound or plant extract. All samples showed a dose dependent inhibition of DPPH radicals as shown in Fig. 1. Among the samples, G.heyneanum var. heyneanum showed significant antioxidant activity with $\mathrm{IC}_{50}$ of $46.63 \pm 2.26 \mu \mathrm{g} / \mathrm{mL}$, comparable to that of standard ascorbic acid with IC 50 value of $48.93 \pm 1.75 \mu \mathrm{g} / \mathrm{mL}$ as shown in Table 3 . 


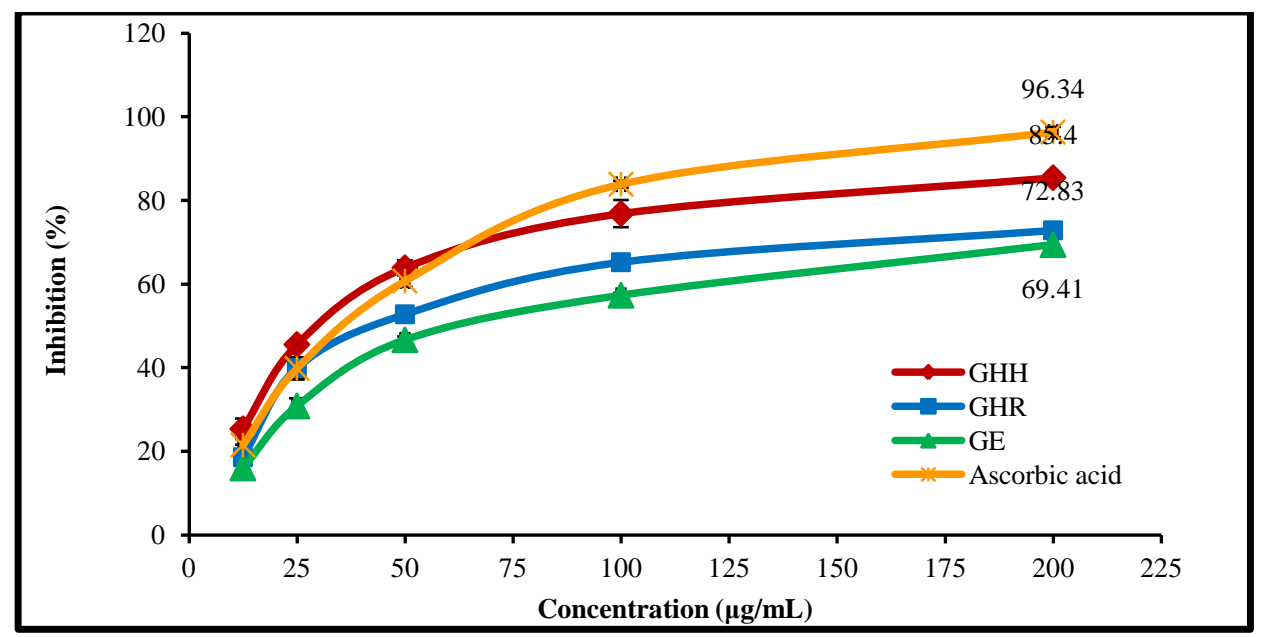

Figure 1: DPPH radical scavenging activity

GHH- G. heyneanum var. heyneanum, GHR- G. heyneanum var. rottleri, GE - G. eriocarpum. Data expressed as Mean \pm SE of three replicates.

\section{Hydroxyl radical scavenging activity}

Hydroxyl radical is the most reactive oxygen species that can attack and damage bio molecules. In the present study all the three extracts showed good scavenging ability. In scavenging hydroxyl radical, both $G$. heyneanum var. heyneanum and G. eriocarpum showed significant activity with higher inhibition percentage and lower $\mathrm{IC}_{50}$ values as compared to standard gallic acid (Table 3). Maximum inhibition for scavenging hydroxyl radical was $78.12 \pm 3.68$ for $G$. eriocapum and $76.87 \pm 3.26$ for $G$. heyneanum var. heyneanum at a concentration of $2000 \mu \mathrm{g} / \mathrm{mL}$ (Fig. 2), which is a clear indication of strong antioxidant property of Gomphostemma spp.

Table 3: IC 50 values of antioxidant assays

\begin{tabular}{|l|l|l|}
\hline \multirow{2}{*}{ Plant } & \multicolumn{2}{|c|}{ IC $\mathbf{5 0}_{\mathbf{0}} \pm \mathbf{S E}(\boldsymbol{\mu g} / \mathbf{m L})$} \\
\cline { 2 - 3 } & DPPH radical scavenging & Hydroxyl radical scavenging \\
\hline GHH & $46.63 \pm 2.26$ & $745.17 \pm 2.13$ \\
\hline GHR & $80.41 \pm 1.87$ & $1108.56 \pm 2.12$ \\
\hline GE & $101.61 \pm 1.22$ & $587.17 \pm 2.97$ \\
\hline Standard & $48.93 \pm 1.75$ & $1347.51 \pm 1.94$ \\
\hline
\end{tabular}

GHH- G. heyneanum var. heyneanum, GHR- G. heyneanum var. rottleri, GE - G. eriocarpum. Data expressed as Mean \pm SE of three replicates.

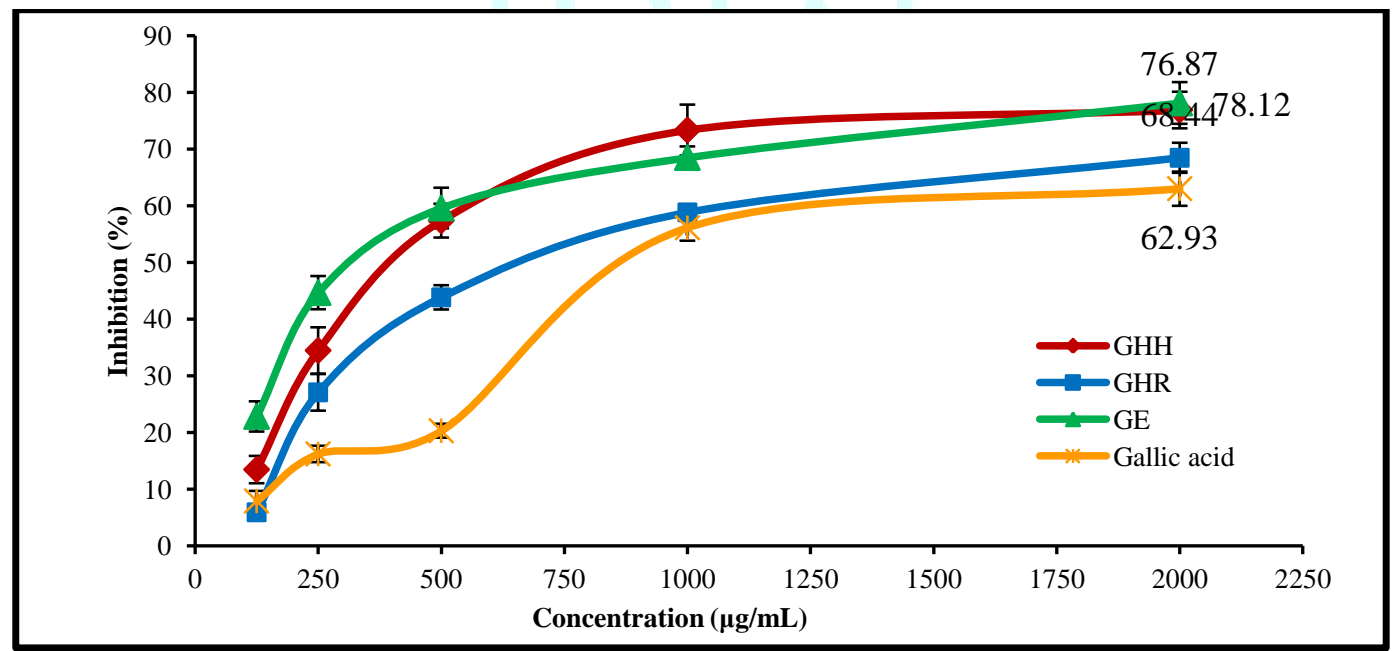

Figure 2: Hydroxyl radical scavenging activity

GHH- G. heyneanum var. heyneanum, GHR- G. heyneanum var. rottleri, GE - G. eriocarpum. Data expressed as Mean \pm SE of three replicates.

\section{Reducing power assay}

Reducing power of samples analysed using potassium ferricyanide method indicated that the reducing ability of extracts increased with increase in concentration as shown by increasing optical density at $700 \mathrm{~nm}$ (Fig. 3). Among the samples tested, $G$. heyneanum var. heyneanum showed maximum reducing potential but less compared to the standard quercetin. 


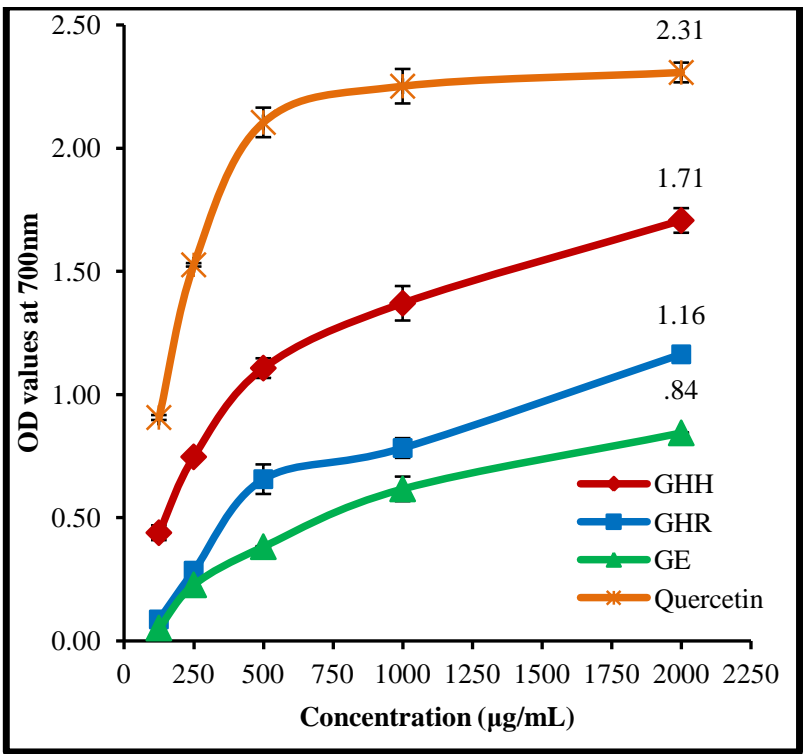

Figure 3: Reducing power activity

GHH- G. heyneanum var. heyneanum, GHR- G. heyneanum var. rottleri, GE - G. eriocarpum.

Data expressed as Mean \pm SE of three replicates.

\section{DISCUSSION}

Plants produce a wide range of bioactive chemical compounds as a result of secondary metabolism. These phytochemicals are considered as the active ingredients attributing therapeutic potential to plant and plant derived products 15. In the present study, selected taxa of Gomphostemma belonging to Lamiaceae was subjected to phytochemical screening, which revealed the presence of a variety of phytoconstituents like phenols, flavonoids, alkaloids, terpenoids and steroids. Presence of such diverse class of phytochemicals can be taken as an indication of the analeptic property of these plants. Phenolic compounds of plant origin are vital in defence responses, such as anti-aging, anti-inflammatory, antioxidant and anti-proliferative activities ${ }^{16}$. Flavonoids from natural sources are considered as an indispensible component in a variety of nutraceutical, pharmaceutical, medicinal and cosmetic applications. This is attributed to their anti-oxidative, anti-inflammatory, anti-mutagenic and anti-carcinogenic properties coupled with their capacity to modulate key cellular enzyme function ${ }^{17}$. In the present study, total phenol and flavonoid contents were estimated to be highest in $G$. heyneanum var. heyneanum. However, $G$ eriocarpum revealed fewer amounts of phenols and flavonoids as compared to other two taxa, but still both were measured in it in significant quantity.

Reactive oxygen species (ROS) are constantly produced in living cells as a result of metabolic reactions. Even though some basic cellular functions are apparently regulated by ROS generated in the cells, excess accumulation may lead to oxidative stress ${ }^{18}$. ROS have been connected with the development and progression of cancer, inflammation and ageing ${ }^{19}$. An antioxidant is any substance which even when present at low concentration significantly delays or prevents oxidation of that substrate 20. Antioxidant capacity is regarded as the ability of a compound to decrease oxidation 21. Antioxidants may be synthetic or natural but safety concerns and limitation on the use of synthetic antioxidants have increased the interest on obtaining natural antioxidants from edible materials, edible by products and residual sources 22 . Many of the natural antioxidants of plant origin belong to phenolic and phenolic class of compounds 23. Phenolic acids are secondary metabolites which are extensively distributed in the plant kingdom and are regarded to be natural antioxidants. Like phenolic acids, flavonoids are secondary metabolites of plants with polyphenolic structure well known for their antioxidant properties ${ }^{24}$. Therefore, determination of total phenolics and flavonoids is helpful in revealing the antioxidant capacity of the plant extracts.

In general, extracts with higher phenolic and flavonoid content shows a higher antioxidant activity because of the antioxidant potential of these class of compounds. In the present study also $G$. heyneanum var. heyneanum which showed a higher phenolic and flavonoid content exhibited significant antioxidant potential in all the three antioxidant assays conducted. However, it is striking to note that $G$. eriocarpum which showed a lower total phenolic and flavonoid content compared to the other two extracts, portrayed a good hydroxyl scavenging ability. This can be attributed to the varied molecular antioxidant response of individual phenolic compounds and the interference from other chemical components of the extract ${ }^{25}$. Current study thus furnishes a lead to the therapeutic potential of selected taxa of Gomphostemma and suggests for extensive studies on these plants.

\section{CONCLUSION}

In the present study selected taxa of Gomphostemma endemic to Western Ghats were screened for their phytoconstituents and antioxidative potential. Preliminary phytochemical analysis revealed the presence of flavonoids, phenols, alkaloids, terpenoids and steroids. Estimation of total phenolics and flavonoids showed a significant amount of these class of compounds which can be taken as a lead for the bioactive and therapeutic efficacy of this taxa. A measurement of antioxidant potential with three comprehensive assays like DPPH scavenging, hydroxyl radical scavenging and reducing power activity showed that Gomphostemma spp. like other members of Lamiaceae are eligible to be considered and can very well be exploited for their therapeutic potential. This is particularly relevant in the present scenario, as there is a constant rise in need for natural products with fewer side effects but with effective therapeutic value for treating and curing many life threatening and life style diseases like cancer, diabetes, hepatic diseases etc. However, detailed research and in depth analysis are required for identifying and isolating the specific compounds which are rendering these plants with their bioactivity potential. Present study thus provides a lead to categorise Gomphostemma spp. as a potent source of therapeutic ingredients.

\section{ACKNOWLEDGEMENT}

The first author gratefully acknowledges University Grants Commission for the award of FIP for doing this research work. The first author is also thankful to the Kerala Forest Department for granting permission to collect specimens from the forest areas.

\section{CONFLICT OF INTEREST}

The authors declare that there are no conflicts of interest. 


\section{REFERENCES}

1. Penna C, Mancardi D, Rastaldo R, Pagliaro P, Cardioprotection: radical view Free radicals in pre and post conditioning, Biochimica et Biophysica Acta (BBA)-Bioenergetics, 2009; 1787(7):781-793.

2. Rahman K, Studies on free radicals, antioxidants, and cofactors, Clinical interventions in aging, 2007; 2(2):219-236.

3. Ray PD, Huang BW, Tsuji Y, Reactive oxygen species (ROS) homeostasis and redox regulation in cellular signalling, Cellular Signalling, 2012; 24(5):981-990.

4. Garhwal S, Medicinal plants as a source of antioxidants, Research Journal of Phytochemistry, 2010; 4(4):213224.

5. Prasad AD, Shyma TB, Raghavendra MP, Plants used by the tribes for the treatment of digestive system disorders in Wayanad district, Kerala, Journal of Applied Pharmaceutical Science, 2013; 3(8):171-175.

6. Dutta B, Study of secondary metabolites of Gomphostemma niveum Hook. f. in Assam, India, Journal of Medicinal Plants, 2014; 2(5):24-28.

7. Sathe M, Kaushik MP, Gomphostenins: two new antimalarial compounds from the leaves of Gomphostemma niveum, Bioorganic \& Medicinal Chemistry Letters, 2010; 20(3):1312-1314.

8. Harborne JB. Phytochemical Methods: a guide to modern techniques of plant analysis. London: Chapman \& Hall Ltd; 1973.

9. Trease GE, Evans WC. Pharmacognosy. $15^{\text {th }}$ ed. London: Saunders Publishers; 2002.

10. Oueslati S, Ksouri R, Falleh H, Pichette A, Abdelly C, Legault J, Phenolic content, antioxidant, anti-inflammatory and anticancer activities of the edible halophyte Suaeda fruticosa Forssk., Food Chemistry, 2012; 132(2):943-947.

11. Dewanto $\mathrm{V}, \mathrm{Wu} \mathrm{X}$, Adom KK, Liu RH, Thermal processing enhances the nutritional value of tomatoes by increasing total antioxidant activity, Journal of Agricultural and Food Chemistry, 2002; 50(10):3010-3014.

12. Chang ST, Wu JH, Wang SY, Kang PL, Yang NS, Shyur LF, Antioxidant activity of extracts from Acacia confusa bark and heartwood, Journal of Agricultural and Food Chemistry, 2001; 49(7):3420-3424.

13. Elizabeth K, Rao MNA, Oxygen radical scavenging activity of curcumin, International Journal of Pharmaceutics, 1990; 58(3):237-240.
14. Yen GC, Duh PD, Tsai CL, Relationship between antioxidant activity and maturity of peanut hulls, Journal of Agricultural and Food Chemistry, 1993; 41(1):67-70.

15. Bernhoft A, A brief review on bioactive compounds in plants, In: Proceedings of Bioactive compounds in plants - benefits and risks for man and animals Oslo, Norway: The Norwegian Academy of Science and Letters; 2010.

16. Lin D, Xiao M, Zhao J, Li Z, Xing B, Li X, Kong M, Li L, Zhang Q, Liu Y, Chen H, An overview of plant phenolic compounds and their importance in human nutrition and management of type 2 diabetes, Molecules, 2016; 21(10):1374.

17. Panche AN, Diwan AD, Chandra SR, Flavonoids: an overview, Journal of nutritional science, 2016; 5:1-15.

18. Robb EL, Christoff CA, Maddalena LA, Stuart JA, Mitochondrial reactive oxygen species (ROS) in animal cells: relevance to aging and normal physiology, Canadian Journal of Zoology, 2013; 92(7):603-613.

19. Wettasinghe M, Shahidi F, Scavenging of reactive-oxygen species and DPPH free radicals by extracts of borage and evening primrose meals, Food Chemistry, 2000; 70(1):17-26.

20. Halliwell B, Gutteridge JM. Free radicals in biology and medicine. Oxford, UK: Oxford University Press; 2015.

21. Opitz SE, Smrke S, Goodman BA, Yeretzian C. Methodology for the measurement of antioxidant capacity of coffee: A validated platform composed of three complementary antioxidant assays. In: Processing and Impact on Antioxidants in Beverages. England: Academic press; 2014. P. 253-264.

22. Shahidi F, Ambigaipalan P, Phenolics and polyphenolics in foods, beverages and spices: Antioxidant activity and health effects-A review, Journal of functional foods, 2015; 18:820-897.

23. Shahidi F. Antioxidants: Principles and applications. In: Handbook of Antioxidants for Food Preservation. Cambridge, U K: Woodhead publishing; 2015, P. 1-14.

24. Ghasemzadeh A, Ghasemzadeh N, Flavonoids and phenolic acids: Role and biochemical activity in plants and human, Journal of Medicinal Plants Research, 2011; 5(31): 6697-6703.

25. Saeed N, Khan MR, Shabbir M, Antioxidant activity, total phenolic and total flavonoid contents of whole plant extracts Torilis leptophylla L., BMC Complementary and Alternative Medicine, 2012; 12(1): 221. 